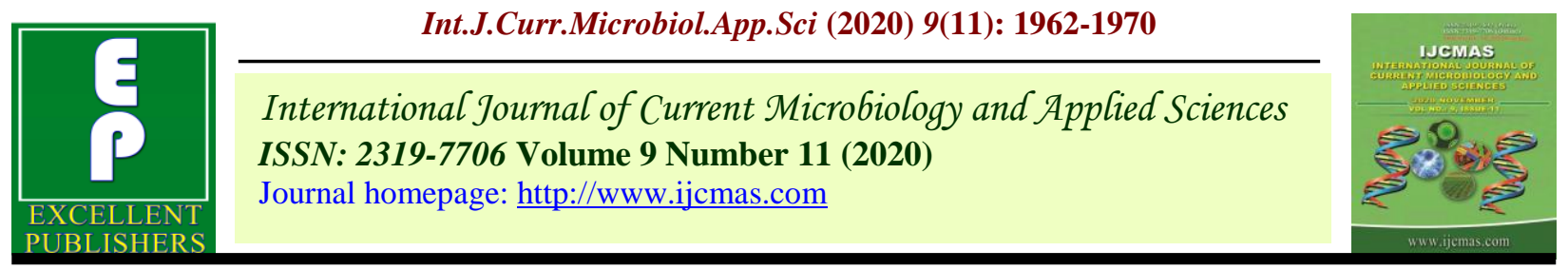

Original Research Article

https://doi.org/10.20546/ijcmas.2020.911.233

\title{
Comparative Microbiome Analysis of Pesticide-Contaminated and Pristine Agricultural Soils of Hot Arid Rajasthan
}

\author{
Anjly Pancholy* and S.K. Singh \\ Central Arid Zone research Institute, Jodhpur (Rajasthan) India \\ *Corresponding author
}

\begin{tabular}{|l|}
\hline K e y w o r d s \\
Microbiome, $16 \mathrm{~S}$ \\
rRNA, Pesticides, \\
Arid soil
\end{tabular}

\begin{abstract}
A B S T R A C T
Comparative microbial community structure analysis of agricultural soil located in hot, western Rajasthan with long term history of chemical pesticides vis-à-vis pristine soil has been attempted using the technique of PCR-RFLP. Pesticidecontaminated (24 nos.) and pristine (10 nos.) soil samples were collected from different locations of the vegetable growing agricultural fields. Metagenomic DNA was extracted each from pooled-contaminated and pooled-pristine soils and amplified with universal 16S rRNA gene primers. Amplification products were cloned in to E. coli DH5 $\alpha$ cells to obtain 78 and $3916 \mathrm{~S}$ rDNA clones from contaminated and pristine soils respectively. The clones were subjected to RFLP analysis using three restriction enzymes (AluI, AvaII and MspI) followed by phylogenetic tree construction. The studies revealed differences in microbial community structures of both types of arid, agricultural soils. We also detected the presence of pesticide-degrading naphthalene dioxygenase gene (nahA) controlling the initial step of the degradation process in contaminated soil.
\end{abstract}

\section{Introduction}

Microorganisms play a crucial role in the degradation of organic compounds and are therefore very important for the mineralization or detoxification of toxic organic chemicals. Numerous field tests and laboratory experiments have identified many harmful organic compounds which biodegrade very slowly (Alharbi, 2018, Speight, 2017) thereby persisting in the environment for long periods. Besides physicochemical conditions, the low biodegradability could be due to low number or complete absence of m.o. present in the natural environment to metabolize the pollutants effectively (Huang et al., 2018; Doolotkeldieva et al., 2018). Nevertheless, microbial communities exposed to xenobiotic compounds for long periods adapt to these chemicals, and m.o. that metabolize them completely and at considerable rates have been isolated (Iqbal and Bartakke, 2014; Akbar and Sultan, 2016). Pesticide degradation usually involves more than one microorganisms and each m.o. contributes to 
biodegradation reactions (Doolotkeldieva et al., 2018). Therefore, characterization of individual m.o. isolated from the natural environment has its limitations for a proper assessment of different genetic events in the adaptive response of bacteria in their natural environment. A comparative characterization involving microbiomes present in contaminated as well as pristine agricultural soils is important to assess a particular bioremediation process as well as understanding of the mechanisms in nature to deal with the persistent organic pollutants. Culturedependent methods are not capable of thoroughly depicting the existing microbial diversity in the biosphere (Austin, 2017) since more than $99 \%$ of the potentially $10^{11}-10^{12}$ microbial species on Earth are unculturable and undiscovered (Bodor et al., 2020; Locey and Lennon, 2016). There is an emerging need to learn more about the missing species through culture-independent approach, since these have great environmental sustainability potential for bioremediation purposes (Epstein, 2013). A comparative analysis of microbiomes of pesticide contaminated and pristine soil is also important to give us an idea as to which m.o. were enriched in soil following contamination and which ones were already present. $16 \mathrm{~S}$ rDNA clone library preparation is suitable technique for obtaining overall information about the genetic diversity and community structure of m.o., including unculturable bacteria in an environment (Marzorati et al., 2008). Several authors have successfully performed PCR-RFLP analyses to assess genetic diversity among bacterial species in the past (Rahmanifar et al., 2012; Mandakovic et al., 2016) in environmental samples. Desert soils are particularly problematic where leaching of pesticides is low due to scanty rainfall resulting in persistence of slowly degradable chemicals (Devi et al., 2018). There is hardly any report from arid western Rajasthan that involves studying changes in the beneficial microbial diversity and composition as a result of indiscriminate usage of pesticides in agricultural soil. Therefore, the present study was undertaken to assess the genetic diversity in microbial populations of pesticidecontaminated arid agricultural soil vis-a-vis uncontaminated or pristine soil of Jodhpur district of western Rajasthan. In a parallel study, we also analyzed the presence of naphthalene degraders by amplification of nahA component of naphthalene dioxygenase gene coding for Naphthalene 1, 2dioxygenase reductase (Ferrero et al., 2002) in the contaminated soil sample.

\section{Materials and Methods}

\section{Soil source and characteristics}

Pesticide contaminated soil cores weighing approximately $10 \mathrm{gm}$ were obtained from 0$15 \mathrm{~cm}$. depth from 24 different sites covering three villages namely Tinvri, Balarwa and Indroka of hot, arid western Rajasthan, India (Latitude, longitude; 24-300N, 70-76.20E). The 24 soil samples were from 12 fields, 2 samples / field, and 4 fields / village, each village situated within a radius of $25 \mathrm{~km}$ from the other. The selected fields were mostly growing chilli, groundnut and mustard in different combinations. The pesticides commonly used were carbofuran, thiram, dinocap, carbendazim, dimethoate for chilli; chlorpyriphos, imidacloprid for groundnut and quinalphos, monocrotofos for mustard to name a few. For comparison, pristine soil samples were also collected from ten different locations from agricultural fields with no history of pesticide usage from the same agroclimatic zone. For ensuring maximum microbial diversity, both the contaminated and the pristine soil samples were pooled separately and mixed thoroughly before further analysis. Major soil characteristics of sampling sites were loamy, sandy soil with sand $87.2 \%$, silt $5.2 \%$ and clay $7.1 \%$. The $\mathrm{pH}$ 
of the soil was in the range of 8.1 to 8.5 with Ece $0.088 \mathrm{ds} / \mathrm{m}-1$. The soil samples were kept in the cold room in sterile sample bags at $4^{\circ} \mathrm{C}$ until used.

\section{Metagenomic soil DNA extraction}

The DNA extraction method was a modified version of the direct lysis method [Saano et $a l ., 1995]$ which was briefly as follows- To $1 \mathrm{~g}$ of soil sample in a $15 \mathrm{ml}$ polypropylene tube was added $2.5 \mathrm{ml}$ of the following buffer- 120 $\mathrm{mM} \mathrm{Na} 2 \mathrm{HPO}_{4}(\mathrm{pH} \mathrm{8.0)}, 1 \%$ sodium dodecyl sulphate $(\mathrm{SDS}), 100 \mu \mathrm{g} \mathrm{ml} \mathrm{m}^{-\mathrm{I}}$ proteinase $\mathrm{K}+$, mixed well and incubated for $1 \mathrm{~h}$ at $37^{\circ} \mathrm{C}$ with occasional shaking. $450 \mu \mathrm{l}$ of $5 \mathrm{M}$ sodium chloride was then added followed by vortexing and addition of $375 \mu 1$ of $10 \%$ cetyl trimethyl-ammonium bromide in $0.7 \mathrm{M} \mathrm{NaCl}$ and incubation at $65^{\circ} \mathrm{C}$ for $20 \mathrm{~min}$. Chloroform was added in equal volume followed by vortexing. The mixture was centrifuged for $15 \mathrm{~min}$. at $9000 \mathrm{xg}$ at $4^{\circ} \mathrm{C}$. The water phase was collected into a fresh tube and an equal volume of absolute alcohol was added, mixed and incubated for $1 \mathrm{~h}$ at $-20^{\circ} \mathrm{C}$ followed by $70 \%$ ethanol wash. It was then centrifuged for $5 \mathrm{~min}$ and the DNA pellet was dried. The amount of DNA extracted was estimated by electrophoresis of $2 \mu 1$ aliquot on a $0.8 \%$ agarose gel.

\section{PCR amplification and cloning}

PCR was performed to amplify bacterial $16 \mathrm{~S}$ rRNA and naphthalene dioxygenase (nahA) gene sequences using metagenomic soil DNA. Universal rDNA primers- Eub1(5'AG AG TTT GAT CCT GG CTCA 3') and Eub2 (5'GCTCGTTGCGGGACTTATCC 3') from Eubacteria and naphthalene dioxygenase gene primers (NA-1-1/F 5'GATGTTCGCG CTCGGA3' and NA-1-1/R 5' AGCTGCT GACGTGTG 3') from Pseudomonas putida were used for amplification purpose. All PCR amplifications were performed with Taq DNA polymerase (Bangalore Genei) in PERKIN
ELMER GeneAmp PCR System using following steps; an initial denaturation for 5 min. at $94^{\circ} \mathrm{C}, 35$ amplification cycles of denaturation $\left(30 \mathrm{~s}\right.$ at $\left.94^{\circ} \mathrm{C}\right)$, annealing $(30 \mathrm{~s}$ at $55^{\circ} \mathrm{C}$ ) and elongation (30s at $72^{\circ} \mathrm{C}$ ) and a final extension step of $7 \mathrm{~min}$. at $72^{\circ} \mathrm{C}$. The PCR products were purified by running on low melting point agarose (1\%), followed by elution of bands and phenol-chloroformalcohol purification of the DNA. Plasmid clones were generated by blunt end ligation of the PCR product with PUC 19 at the Sma I site after end filling with klenow fragment of DNA polymerase I. The ligation products were transformed into Escherichia coli $\mathrm{DH} 5 \alpha$ competent cells and the selection of the transformants containing the inserts was done on Luria agar plates containing ampicillin $\left(100 \mu \mathrm{g} / \mathrm{ml}^{-1}\right)$ in presence of $50 \mu \mathrm{I} \mathrm{x}$-gal (stock- $20 \mathrm{mg} / \mathrm{ml}$ in dimethyl formamide) for blue-white color selection. White colonies selected were inoculated into luria broth containing ampicillin. The cultures were grown overnight and plasmid minipreps were done. The plasmid preps showing higher molecular weight on the electrophoresis gel as compared to the vector were further confirmed as recombinant clones by restriction enzyme digestion with Hind III and Eco R1 which cut the vector PUC 19 on either side of Sma I site to release the insert.

\section{Restriction fragments analysis or ribotyping}

Five $\mu$ l aliquot of each plasmid DNA having cloned 16S rRNA gene were digested with three different restriction enzymes namely AluI, AvaII, and MspI (New England Biolabs,) according to the manufacturer's instructions in a $25 \mu 1$ system. In case of nahA gene clones, instead of AvaII, Sau3AI was used, the other two enzymes were the same. The enzymes were inactivated by heating the reaction mixture at $65^{\circ} \mathrm{C}$ for $15 \mathrm{~min}$. The digestion products were analyzed on horizontal agarose (Gibco BRL) gel (1.5\% 
w/v) electrophoresis with TBE buffer (1x) containing ethidium bromide $(0.5 \mathrm{mg} / \mathrm{ml})$. Electrophoresis was carried out at $80 \mathrm{~V}$ for 3 $\mathrm{hr}$ in $11 \times 14 \mathrm{~cm}$ gel. The gels were viewed and photographed under UV illumination. Clones with similar pattern of digestion and intensity generated from a particular restriction enzyme were put in to the same ribotype group.

\section{Phylogenetic analysis}

Genetic relationship between two amplified $16 \mathrm{~S}$ rRNA (ribotypes) and nahA genes was evaluated by determining the presence or absence of a particular DNA restriction pattern for a given enzyme. Dice similarity coefficient based on proportion of shared restriction patterns was calculated, distance matrix determined and distance values were displayed as a dendrogram by using the unweighted pair group method with arithmetic mean (UPGMA) using NT Sys-Pc package (Exter Corp., USA). Cluster analysis was done using Neighbour-joining option of the same package.

\section{Results and Discussion}

\section{Metagenomic soil DNA extraction}

The sample soil was clay loam in texture and alkaline in nature ( $\mathrm{pH}$ 8.0). The typical feature of alkaline soils or sediments is the presence of low level of microbial biomass (Verma and Satyanarayana 2011). But the DNA obtained by the method used in the present study (pooling of soil samples from all 24 locations) was sufficient as well as suitable for PCR amplification and also ensured diversity of rDNA clones obtained. Use of metagenomic molecular-based approach not only circumvented the limitation of culture-based approach but also revealed vast diversity of microbes from soil sample. Similar results were also reported by Daniel (2005).

\section{PCR amplification and cloning}

The primer set used in the present study targets and amplifies the 16S rRNA gene present in majority of the environmental bacterial groups (Huws et al., 2007). The extracted metagenomic DNA from soil samples was amplified with the $16 \mathrm{~S}$ ribosomal primers and a $16 \mathrm{~S}$ rDNA clone library with 117 clones in E. coli DH5 $\alpha$ cells was constructed from pesticide contaminated and non-contaminated soils. Authenticity of the recombinant clones was confirmed by subjecting the clones to restriction digestion with HindIII and EcoRI enzymes to release $1.1 \mathrm{~Kb}$ inserts from the vector. The nahA gene amplification produced bands of $393 \mathrm{bp}$ size and total 7 clones were obtained.

\section{RFLP analysis or ribotyping}

Ribotyping is the identification and classification of bacteria based on polymorphisms in universal and highly conserved ribosomal RNA molecules or their genes (Bouchet et al., 2008). The 78 rDNA clones from the pesticide-contaminated and 39 from the non-contaminated soil were cut with restriction endonucleases namely AluI, AvaII and MspI having internal sites in the 16S rRNA gene. PCR-RFLP method has been used previously by several workers to distinguish and identify bacteria to species and strain level (Kashyap et al., 2014; Mandakovic et al., 2016). Three restriction endonucleases gave different numbers of distinct restriction patterns - AluI (15), MspI (18) and AvaII (12) in both types of soils combined together (Table 1).

The restriction patterns obtained were then compared to generate 27 different combinations representing 27 16S rDNA genotypes (or ribotypes) from 78 rDNA clones obtained from the contaminated soil and 16 ribotypes from the uncontaminated soil (Table 1). 
Table.1 RFLP patterns (ribotypes) obtained by restriction analysis of cloned 16S rRNA gene from two types of soil

\begin{tabular}{|c|c|c|c|c|c|c|c|}
\hline \multicolumn{4}{|c|}{ Contaminated soil } & \multicolumn{4}{|c|}{ Pristine soil } \\
\hline \multirow[t]{2}{*}{ Ribotypes } & \multicolumn{3}{|c|}{$\begin{array}{c}\text { Restriction fragments } \\
\text { patterns }\end{array}$} & \multirow[t]{2}{*}{ Ribotypes } & \multicolumn{3}{|c|}{$\begin{array}{c}\text { Restriction } \\
\text { fragments patterns }\end{array}$} \\
\hline & AluI & MspI & AvalI & & AluI & MspI & AvaII \\
\hline $\mathrm{R}-1(4) *$ & A1 & M1 & Av1 & $\mathrm{r}-1(2)$ & A6 & M17 & Av4 \\
\hline $\mathrm{R}-2(2)$ & A2 & M2 & Av1 & $r-2(4)$ & A6 & M8 & Av11 \\
\hline $\mathrm{R}-3(3)$ & A7 & M3 & Av1 & $\mathrm{r}-3(3)$ & A14 & M18 & Av12 \\
\hline $\mathrm{R}-4(2)$ & A7 & M3 & Av6 & $r-4(2)$ & A3 & M18 & Av12 \\
\hline $\mathrm{R}-5(2)$ & A7 & M3 & Av4 & $r-5(2)$ & A3 & M17 & Av11 \\
\hline $\mathrm{R}-6(2)$ & A4 & M4 & Av1 & $r-6(3)$ & A6 & M18 & Av12 \\
\hline R-7(3) & A4 & M5 & Av4 & $\mathrm{r}-7(2)$ & A14 & M17 & Av12 \\
\hline $\mathrm{R}-8(4)$ & A4 & M13 & Av2 & $\mathrm{r}-8(3)$ & A15 & M18 & Av12 \\
\hline $\mathrm{R}-9(2)$ & A4 & M4 & Av2 & $r-9(3)$ & A7 & M3 & Av6 \\
\hline R-10(2) & A4 & M11 & Av1 & $\mathrm{r}-10(2)$ & A4 & M13 & Av2 \\
\hline R-11(1) & A4 & M10 & Av1 & $\mathrm{r}-11(1)$ & A4 & M10 & Av1 \\
\hline R-12(12) & A6 & M7 & Av2 & $r-12(3)$ & A6 & M14 & Av11 \\
\hline $\mathrm{R}-13(2)$ & A6 & M14 & Av11 & $\mathrm{r}-13(1)$ & A5 & M12 & Av4 \\
\hline $\mathrm{R}-14(1)$ & A3 & M6 & Av3 & $r-14(2)$ & A7 & M3 & Av1 \\
\hline $\mathrm{R}-15(2)$ & A5 & M12 & Av4 & $r-15(3)$ & A5 & M12 & Av5 \\
\hline R-16(1) & A5 & M12 & Av5 & $\mathrm{r}-16(3)$ & A12 & M15 & Av7 \\
\hline R-17(3) & A9 & M8 & Av9 & & & & \\
\hline R-18(2) & A9 & M8 & Av11 & & & & \\
\hline R-19(3) & A12 & M15 & Av7 & & & & \\
\hline R-20(4) & A10 & M16 & Av8 & & & & \\
\hline $\mathrm{R}-21(2)$ & A11 & M9 & Av1 & & & & \\
\hline $\mathrm{R}-22(2)$ & A13 & M8 & Av1 & & & & \\
\hline $\mathrm{R}-23(2)$ & A13 & M10 & Av6 & & & & \\
\hline $\mathrm{R}-24(7)$ & A8 & M12 & Av10 & & & & \\
\hline $\mathrm{R}-25(3)$ & A5 & M14 & Av1 & & & & \\
\hline $\mathrm{R}-26(2)$ & A5 & M14 & Av4 & & & & \\
\hline R-27(3) & A4 & M4 & Av1 & & & & \\
\hline
\end{tabular}

*Numbers in parentheses are the numbers of each ribotypes 
Fig.1 Dendrogram (UPGMA) of genetic relationships among 16S rRNA ribotypes identified by PCR-RFLP analysis. The ribotypes (R1-27 \& r1-16) are defined in Tables 1

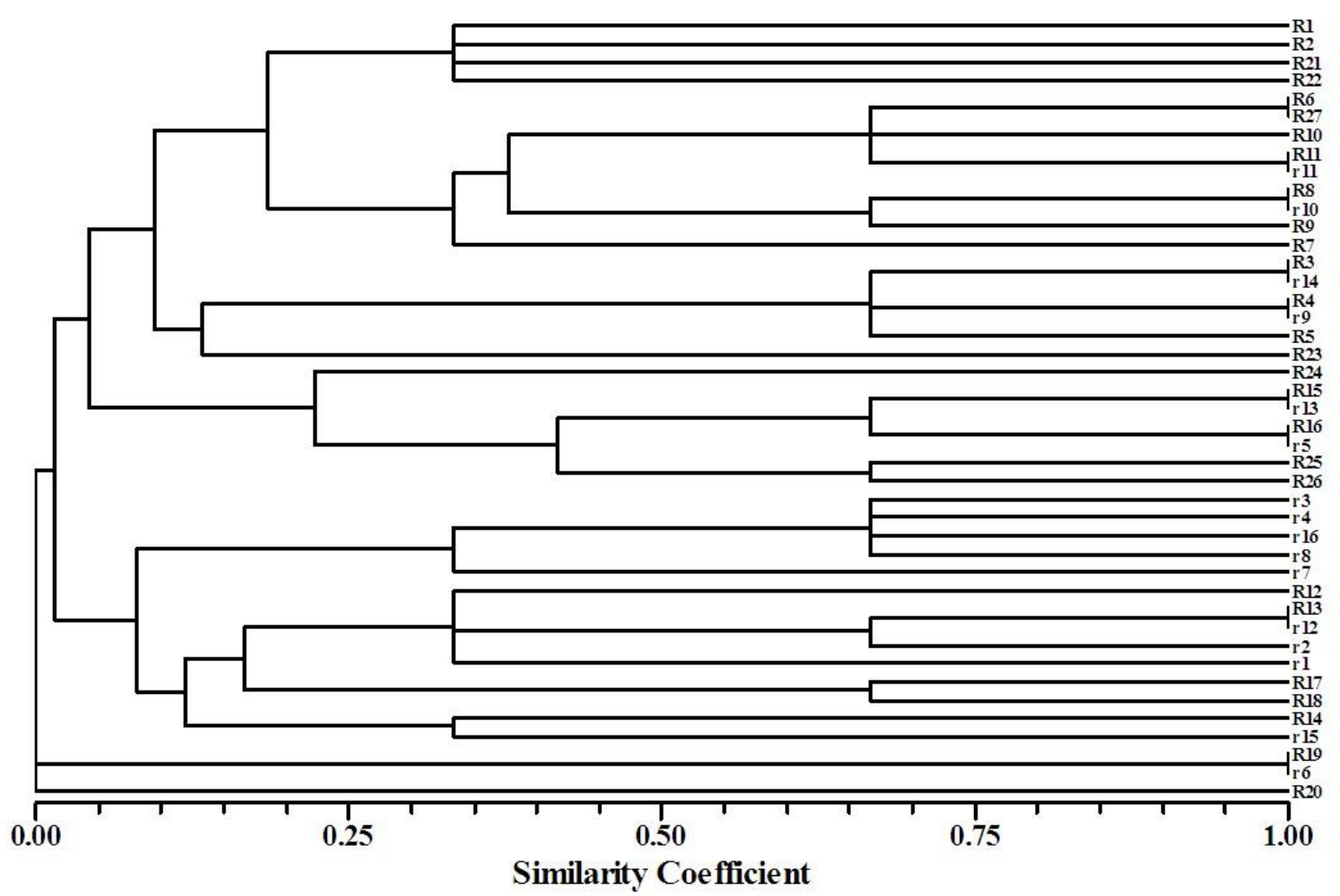

The numbers in parentheses show the numbers of rDNA clones sharing a particular ribotype. Ribotype R-12 and R-24 appeared more frequently (12 and 7 times respectively) as compared to others indicating their relative abundance in the soil. Partial sequence (350 $\mathrm{bp)}$ of one representative clone each from the R-12 and R-24 revealed Sphingomonas sps. and Bacteroides uniformis respectively as the closest matches. Sphingomonas sps has been found to degrade carbofuran and carbofuran7-phenol by hydrolysis at the Furanyl Ring (Seon et al., 2004). Seven nahA gene clones were digested with restriction enzymes AluI, MspI and Sau3AI. The RFLP pattern obtained by restriction enzymes indicated all 7 nahA clones to be identical. Amplification of nahA gene from contaminated soil pointed towards the presence of naphthalene degraders in the analysed soil sample.

\section{Genotypic relationships among ribotypes}

To estimate the genotypic relationships, a matrix of pair-wise genetic distances was produced for all the ribotypes obtained from both types of soils. The distance matrix was then used to construct a dendrogram based on neighbour-joining algorithm (Fig. 1). The ribotypes represented by ' $R$ ' were from the soil of contaminated sites and those from the uncontaminated sites were represented by 'r'. As evident from Fig. 1, the ribotypes $r-1, r-2$, $\mathrm{r}-3, \mathrm{r}-4, \mathrm{r}-7, \mathrm{r}-8$ and $\mathrm{r}-16$ formed separate clusters and thus seem to be unique to the pesticide-free soil, indicating disappearance 
of certain microbes in the soil post contamination by toxic pesticides. Large number of ribotypes (R1, R2, R5, R6, R7, R9, R10, R12, R17, R18, R20, R21，R22，R23, R24, R25, R26 and R27) were either present singly or clustering among themselves in the dendrogram and so, appeared to be concentrated in the contaminated soil samples. Other workers have also reported that presence of some pesticides favour specific type of microbial population in the soil environment (Chen and Edwards, 2001; Nasreen et al., 2015). On the other hand, certain ribotypes in pairwise combinations from both the soils were found to be clustered together with high bootstrap values (R-3 \& r14; R-4 \& r-9; R-8 \& r-10; R11 \& r11; R13 \& r12; R14 \& r15; R15 \& r13; R16 \& r5; R19 \& r6) indicating their concurrent presence in both types of soils.

To determine the possible whole range of microbial diversity, various strategies were applied in the present study which included isolation of bulk DNA by direct lysis of bacteria within their natural habitat to recover more representative fraction of the genetic diversity, selection of oligo-nucleotide primer pair to cover broad range of bacteria, and use of Restriction Fragment Length Polymorphism, one of the most useful molecular technique for diversity analysis in terms of cost effectiveness and reliability (Gayathri Devi and Ramya, 2015). Comparative microbiome analysis in the present study clearly indicated that there was alteration in microbial diversity and composition in the contaminated soil environment as a result of long term indiscriminate use of pesticides. Such alteration in the beneficial microbial community can be unfavorable to plant growth and development either by reducing nutrient availability or by increasing disease incidence (Meena, 2020). The selected ribotypes and degrader types in the present study represented the most abundant and active species. With the help of the genetic relationships and the distance values estimated in the present study, the ribotypes and the degrader types can be used as habitatspecific probes for further studies depending upon the assessment or the characterization work to be undertaken.

\section{Acknowledgments}

Authors are thankful to Director CAZRI for providing facilities during the period of this study.

\section{References}

Austin, B. (2017). The value of cultures to modern microbiology. Antonie van Leeuwenhoek Int J Gen Mol Microbiol. https://doi.org/10.1007/s10482- 0170840-8.

Akbar, S., Sultan, S. (2016). Soil bacteria showing a potential of chlorpyrifos degradation and plant growth enhancement. Braz. J. Microbiol., 47: 563- 570 .

Alharbi O.M.L., Basheer, A. A., Khattab, R. A., Ali, I. (2018) Health and environmental effects of persistent organic pollutants. J. Mol. Liq., 263: 442-453.

Bodor, A., Bounedjoum, N., Vincze, G.E. et al., (2020). Challenges of unculturable bacteria: environmental perspectives. Rev. Environ. Sci. Biotechnol., 19: 122.

Bouchet, V., Huot, H., Goldstein, R. (2008). Molecular genetic basis of ribotyping. Clin Microbiol Rev., 21(2): 262-273. doi:10.1128/CMR.00026-07

Chen, S.K., Edwards, C.A. (2001). A microcosm approach to assess the effects of fungicides on soil ecological processes and plant growth: Comparison of two soil types. Soil Biol. 
Biochem., 33: 1981-1991.

Daniel, R. (2005). The metagenomics of soil. Nature Rev., 3: 470-477.

Doolotkeldieva, T., Konurbaeva, M., Bobusheva, S. (2018). Microbial communities in pesticide-contaminated soils in Kyrgyzstan and bioremediation possibilities. Environ. Sci. Pollut. Res., 25: 31848-31862.

Devi, Y.B., Meetei, T.T., Kumari, N. (2018). Impact of pesticides on soil microbial diversity and enzymes: A Review. Int. J. Curr. Microbiol. Appl. Sci., 7(6): 952-958.

Epstein, S. S. (2013). The phenomenon of microbial uncultivability. Curr. Opin. Microbiol. 16: 636-642. https://doi.org/10. 1016/j.mib.2013.08.003

Ferrero, M., Llobet-Brossa, E., Lalucat, J., García-Valdés, E., Rosselló- Mora, R., Bosch, R. (2002). Coexistence of two distinct copies of naphthalene degradation genes in Pseudomonas strains isolated from the western Mediterranean region. Appl. Environ. Microbiol., 68(2): 957-962.

Gayathri D. S., Ramya M. (2015). PCRRFLP based bacterial diversity analysis of a municipal sewage treatment plant. J. Environ. Biol., 36: 1113-1118.

Huang. Y, Xiao, L., Li, F., Xiao, M., Lin, D., Long, X., Wu, Z. (2018). Microbial degradation of pesticide residues and an emphasis on the degradation of cypermethrin and 3-phenoxy benzoic Acid: A Review. Molecules, 23(9): 2313

Huws, S. A., Edwards, J. E., Kim, E. J., Scollan, N. D. (2007). Specificity and sensitivity of eubacterial primers utilized for molecular profiling of bacteria within complex microbial ecosystems. J. Microbiol. Methods., 70(3): $565-$ 9. doi: 10.1016/j.mimet.2007.06.013.
Iqbal, M.A., Bartakke, K.V. (2014). Isolation of pesticide degrading microorganisms from soil. Adv. Biores., 5(4): 164-168.

Kashyap, S.K., Maherchandani, S., Kumar, N. (2014). Ribotyping: A tool for molecular taxonomy in "Animal Biotechnology" Ed. Ashish S. Verma and Anchal Singh, Science Direct.

Locey, K. J., Lennon, J. T. (2016). Scaling laws predict global microbial diversity. Proc. Natl. Acad. Sci. USA, 113: 59705975. https://doi.org/10.1073/pnas.152129111 3

Mandakovic, D., Glasner, B., Maldonado, J. et al., (2016). Genomic-Based restriction enzyme selection for specific detection of Piscirickettsia salmonis by $16 \mathrm{~S}$ rDNA PCR-RFLP. Frontiers in Microbiology. 7: 1-12.

Marzorati, M., Wittebolle, L., Boon, N. et al., (2008) How to get more out of molecular fingerprints: practical tools for microbial ecology. Environ. Microbiol., $\quad 10: 1571-\quad 1581$. https://doi.org/ 10.1111/j.1462 2920.2008.01572.x

Meena, R. S., Kumar, S., Datta, R., Lal, R., et al., (2020). Impact of Agrochemicals on soil microbiota and management: A Review. Land. 9: 34.

Nasreen, G., Mohiddin, J., Srinivasulu, M., Manjunatha, B., Rangaswamy, V. (2015). Interaction effects of insecticides on microbial populations and dehydrogenase activity in groundnut (Arachis hypogeae L.) planted black clay soil $\mathrm{C}$. International Journal of Current Microbiology and Applied Sciences. 4(2): 135-146.

Rahmanifar, B., Hasanzadeh, N., Razmi, J., Ghasemi, A. (2012). Genetic diversity of Iranian potato soft rot bacteria based on polymerase chain reaction-restriction fragment length polymorphism (PCRRFLP) analysis. African Journal of 
Biotechnology. 11(6): 1314-1320.

Saano, A., Tas, E., Pippola, S., Lindstrom, K., Elsas, J. D. van. (1995). Extraction and analysis of microbial DNA from soil. In: Nucleic acids in the Environment: Methods and Applications. Eds. J. T. Trevers, J. D. van Elsas.

Seon, K.I., Ryu, J. Y., Hur, H. G., Gu, M. B., Kim, S. D., Shim, J. H. (2004). Sphingomonas sp. strain SB5 degrades carbofuran to a new metabolite by hydrolysis at the furanyl ring. J. Agric. Food Chem., 52(8): 2309-2314.
Speight, J. G. (2017). Removal of organic compounds from the environment

Editor(s): James G. Speight, Environmental Organic Chemistry for Engineers, Butterworth-Heinemann, Pages 387432.

Verma, D., Satyanarayana, T. (2011) An improved protocol for DNA extraction from alkaline soil and sediment samples for constructing metagenomic libraries. Appl. Biochem. Biotechnol., 65: 454464.

\section{How to cite this article:}

Anjly Pancholy and Singh, S.K. 2020. Comparative Microbiome Analysis of PesticideContaminated and Pristine Agricultural Soils of Hot Arid Rajasthan. Int.J.Curr.Microbiol.App.Sci. 9(11): 1962-1970. doi: https://doi.org/10.20546/ijcmas.2020.911.233 